\title{
ESSENTIAL NORM OF WEIGHTED COMPOSITION FOLLOWED AND PROCEEDED BY DIFFERENTIATION OPERATOR FROM BLOCH-TYPE INTO BERS-TYPE SPACES
}

\author{
HAMID VAEZI AND MOHAMAD NAGHLISAR*
}

\begin{abstract}
We consider the weighted composition followed and proceeded by differentiation operator $D C_{\varphi}^{u} D$ from Bloch-type space $B^{\alpha}$ into Bers-type space $H_{\beta}^{\infty}$. First, we give necessary and sufficient conditions for boundedness and compactness of this operator. Then, we obtain the essential norm estimate of such an operator in terms of $u$ and $\varphi$.
\end{abstract}

Mathematics subject classification (2020): 47B33, 30H30, 30H99.

Keywords and phrases: Weighted composition operator, Bloch-type space, Bers-type space, essential norm.

\section{REFERENCES}

[1] F. Colonna And S. LI, Weighted composition operator from the Besov spaces to the Bloch spaces, Bull Malaysian Sci. Soc. 36, 4 (2013), 1027-1039.

[2] C. C. Cowen AND B. D. MaCCluer, Composition operators on spaces of analytic functions, Studies in Advanced Mathematics, CRC Press, Boca Raton, 1995.

[3] X. C. Gui And Z. H. Zhou, New characterizations for weighted composition operator from Zygmund type spaces to Bloch type spaces, Czechoslovak Math. J. 65, 2 (2015), 331-346.

[4] M. HASS ANLOU, H. VAEZI AND M. WANG, Weighted composition operators on weak vector-valued Bergman spaces and Hardy spaces, Banach J. Math. Anal. 9, 2 (2015), 35-43.

[5] R. A. Hibschweiler And N. Portnoy, Composition by differentiation between Bergman and Hardy spaces, Can. J. Math. 38 (1986), 878-906.

[6] S. LI, E. ABBASI AND H. VAEZI, Weighted composition operators from Bloch-type spaces to nth weighted-type spaces, Ann. Polon. Math. 124, 1 (2020), 93-107.

[7] S. Li AND S. STEVIC, Composition followed by differeniation between Bloch-type spaces, J. Comput. Anal. and Appl. 9, 2 (2007), 195-205.

[8] J. LONG, C. QIU AND P. WU, Weighted composition followed and proceeded by differentiation operators from Zygmund spaces to Bloch-type spaces, J. Inequal. Appl. 2014 (2014), 12 pages.

[9] B. D. MACCLUER AND R. ZHAO, Essential norms of weighted composition operators between Blochtype spaces, Rocky mountain J. Math. 33, 4 (2003), 1437-1458.

[10] J. S. Manhas AND R. ZhaO, Products of weighted composition and differentiation operators into weighted Zygmund and Bloch spaces, Acta Math. Sci. 38, 4 (2018), 1105-1120.

[11] S. OHno, Products of composition and differentiation between Hardy spaces, Bull. Austral. Math. Soc. 73, 2 (2006), 235-243.

[12] S. Ohno, K. Stroethoff And R. Zhao, Weighted composition operators between Bloch-type spaces, Rocky mountain J. Math. 33, 1 (2003), 191-215.

[13] A. M. RodrigueZ, The essential norm of a composition operator on Bloch spaces, Pacific J. Math. 188, 2 (1999), 339-351.

[14] A. SAlaryan AND H. VAEZI, Adjoints of rationally induced weighted composition operators on the Hardy, Bergman and Dirichlet spaces, Period. Math. Hung. 72 (2016), 76-89.

[15] A. H. SANATPOUR AND M. HASSANLOU, Essential norms of weighted composition operators between Zygmund-type spaces and Bloch-type spaces, Turk. J. Math. 38 (2014), 872-882. 
[16] J. H. SHAPIRo, Composition operators and classical function theory, New York, Springer Verlag, 1993.

[17] S. STEVIC, Essential norms of weighted composition operators from the $\alpha$-Bloch space to a weightedtype space on the unit ball, Abstr. Appl. Anal. 2008 (2008), 11 pages.

[18] H. Weixiang and J. Lijian, Composition operator on Bers-type spaces, Acta. Math. Sci. 22B, 3 (2002), 404-412.

[19] S. YAMAJI, Composition operator on the Bergman spaces of a minimal bounded homogeneous domain, Hiroshima Math. J. 43, 1 (2013), 107-128.

[20] R. ZHAO, Essential norms of composition operators between Bloch-type spaces, Proc. Amer. Math. Soc. 138, 7 (2010), 2537-2546.

[21] X. ZHU, Bloch type spaces of analytic functions, Rocky mountain J. Math. 23, 3 (1993), 1143-1177.

[22] X. ZHU, Generalized weighted composition operators from Bloch spaces into Bers-type spaces, Filomat 26, 6 (2012), 1163-1169. 